\title{
Refractive lens exchange using SN60T5 AcrySof Toric intraocular lens in stage 2 keratoconus
}

\author{
Extração do cristalino transparente e uso de \\ lente intraocular tórica SN60T5 AcrySof Toric \\ em ceratocone grau 2
}

Giuliano de Oliveira Freitas', Mário José Carvalho², Joel Edmur Boteon ${ }^{3}$

\begin{abstract}
This is a case report of a 45-year-old anisometropic woman with stage 2 keratoconus submitted to refractive lens exchange employing SN60T5 AcrySof Toric intraocluar lens on her left eye. Phacoemulsification followed by proper lens implantation was accomplished successfully. On postoperative period, favorable refractive and visual outcomes were obtained. The use of toric intraocular lenses may be an option in the refractive treatment of stage 2 keratoconus in selected cases.

Keywords: Keratoconus; Lens implantation, intraocular; Anisometropi; Lens, crystalline/surgery; Case reports

\section{ResUMO}

Relatamos o caso de uma senhora de 45 anos de idade, portadora de ceratocone grau 2 e consequente anisometropia, submetida à extração do cristalino transparente, e uso da lente intraocular modelo SN60T5 AcrySof Toric para o olho esquerdo. Facoemulsificação seguida pelo implante da lente intraocular tórica no olho esquerdo. No pós-operatório, resultados refracionais e visuais satisfatórios foram alcançados. $\mathrm{O}$ uso de lentes intraoculares tóricas pode se constituir em opção terapêutica para casos selecionados de ceratocone grau 2.
\end{abstract}

Descritores: Ceratocone; Implante de lentes intraoculares ; Anisometropia; Cristalino/cirurgia; Relatos de casos

\footnotetext{
${ }^{1} \mathrm{MD}$, Postgraduate Student (Doctorate Degree) at Universidade Federal de Minas Gerais - UFMG - Belo Horizonte (MG), Brazil; ${ }^{2} \mathrm{MD}$, Head of Cataract Surgery staff at ISO Olhos, Uberlandia-(MG),Brazil;

${ }^{3} \mathrm{MD}, \mathrm{PhD}$, Associate Professor of Ophthalmology Department at Universidade Federal de Minas Gerais - UFMG - Belo Horizonte (MG), Brazil.
}

The authors have no financial interest in any of the products mentioned in this article.

Recebido para publicação em 22/11/2010 - Aceito para publicação em 19/3/2011 


\section{INTRODUCTION}

$\mathbf{K}$ eratoconus is a noninflammatory, often progressive, bilateral thinning disease of the cornea. It is characterized by the development of a corresponding protrusion with an apex often located centrally or in an inferior eccentric position ${ }^{1,2}$. To address this problem, there are numerous stratagems; none of them curative, some having more lasting effects than others ${ }^{2}$.

Keratoconus can be associated with astigmatism of variable severity and axial myopia ${ }^{3,4}$ or can induce myopia by increased corneal curvature ${ }^{3}$.

Nonsurgical management can usually provide functional vision in eyes with keratoconus, sometimes indefinitely: soft contact lenses (SCL), rigid gaspermeable contact lenses (RGP), tandem SCL/RGP lenses ("piggyback") and scleral contact lenses can be used to fit an ectatic corneas.

Surgical correction of the spherical and cylindrical errors associated with keratoconus remains a challenge. Laser in situ keratomileusis in keratoconus may cause corneal ectasia. Photorefractive keratectomy has been used by some researchers to treat myopia associated with keratoconus, but thinning of keratoconic corneas raises long-term safety concerns. Phakic lenses are generally not implanted in patients older than 45 years of age. Other techniques, such as intracorneal rings, can improve visual acuity and reduce corneal curvature in keratoconus, but correction of the spherical error is limited. Refractive lens exchange (RLE), also called "clear lens extraction", consists of phacoemulsification of the clear crystalline lens and in-the-bag implantation of an appropriately powered intraocular lens (IOL). It is generally used to correct large spherical errors in patients in the presbyopic age range because it causes loss of accommodation. Myopia associated with keratoconus is not routinely considered an indication for RLE because of difficult IOL power calculation. Despite the difficulties in obtaining accurate preoperative refraction, and keratometric readings, RLE may be indicated for presbyopic patients with higher spherical errors. In such cases, astigmatism can be addressed by a toric $\mathrm{IOL}^{3}$.

\section{Case report}

A 45-year-old woman presented on a routine ophthalmic consultation complaining to be no longer tolerant to contact lens use on her left eye (OS). She was seeking for excimer laser refractive surgery for that eye.
The patient's medical and family histories were unremarkable.

A comprehensive ophthalmic examination was then performed, including uncorrected distance visual acuity (UDVA) of 0.1 (logMAR scale) for her right eye (OD) and worse than 1.3 for her OS. Her manifest refraction was $+0.50-0.75 @ 15$ degrees for OD and $8.00-2.75 @ 75$ degrees for OS, nearly unchanged, if compared to the previous one, prescribed two years before. Best distance spectacle visual acuity (BDSVA) was 0.00 for OD and 0.18 for OS. Slit lamp examination and applanation tonometry revealed no significant findings. Mild posterior vitreous detachment was found on fundoscopic examination.

Computer assisted videokeratoscopy and pachymetry (Orbscan ${ }^{\mathrm{TM}}$ II - Bausch\&Lomb, Inc.) revealed stage 2 keratoconus for OS in accordance to Krumeich's classification ${ }^{1}$ (Figure 1). Mode A-scan (OcuScan ${ }^{\mathrm{TM}}$ - Alcon Labs) revealed axial lengths (AL) of $23.57 \mathrm{~mm}$ for OD and $26.01 \mathrm{~mm}$ for OS.

The patient consented to have RLE performed on her OS after detailed explanation about the procedure was given.

Immersion biometry using SRK-T formula and on line toric calculator software (AcrySof Toric IOL Calculator Online, available at: www.acrysoftoriccalculator.com Alcon Labs, Inc.) yielded a +9.0 diopters SN60T5 AcrySof Toric intraocular lens selection.

An uneventful phacoemulsification with IOL in the bag implantation was accomplished through a temporal $2.2 \mathrm{~mm}$ clear corneal incision, using routine preslice technique under topical anesthesia.

On the first postoperative visit (on the same day of the surgery), the patient had no major complaints and slit lamp inspection showed the IOL perfectly centered and aligned to the intended axis. On postoperative day 2, UDVA was 0.30 and pinhole visual acuity was nearly 0.18 . On postoperative day 12 , her manifest refraction was 0.25-1.50@ 10 degrees and BDSVA was 0.18 for OS. Slit lamp examination under pharmacologic mydriasis showed IOL centration and alignment. Nearly a year and a half later, the patient's manifest refraction for the OS was $-0.25-1.25 @ 10$ degrees, BDSVA was 0.18 . The patient was very happy, wearing reading glasses only.

\section{Discussion}

Anisometropia is a difference in refractive power between two fellow eyes, usually, greater than 2.0 diopters suppressing binocular vision. Anisometropia can be 
corrected with spectacles, contact lenses or with refractive surgery in younger patients. It would best be corrected with lens extraction in older patients ${ }^{6}$. Contact lenses offer a noninvasive approach. However, patients are often unable or unwilling to use them, particularly if there is good vision in the fellow eye. For such patients, surgical options may have to be considered ${ }^{7}$.

Phakic lenses have several anatomical limitations and are generally not implanted in patients older than 45 years, because of progressive convexity of the crystalline lens, which can induce cataract and pigment dispersion, especially with anterior chamber models ${ }^{3}$.

Retinal detachment (RD) is one of the most significant and severe events that can occur after phacoemulsification. The reported incidence of $\mathrm{RD}$ after lens extraction in highly myopic patients varies significantly between studies, from $0.32 \%$ to $1.72 \%$. This reflects the varying definitions of myopia, inclusion and exclusion criteria and length of follow-up. In light of the progress in surgical technique, several studies of RD after cataract extraction in highly myopic eyes have lost relevance. Frequently mentioned potential risk factors for RD after any type of cataract surgery include male sex, patients younger than 50 years of age, intraoperative rupture of the posterior capsule with vitreous loss, presence of atrophic retinal lesions (retinal lattice degeneration), neodymium:YAG laser capsulotomy and AL greater than $26.0 \mathrm{~mm}^{8}$. There is no apparent differences in the risk for postoperative RD compared to idiopathic RD in highly myopic eyes. The risk for RD after cataract surgery in eyes with very high myopia is higher than in emmetropic eyes, however, the relevant risk, lies within the myopic eye itself, not on the surgical procedure. The role of prophylactic argon laser photocoagulation in reducing the risk for pseudophakic RD is under debate ${ }^{9}$. Hence, patients with high degrees of myopia additionally benefit from the refractive correction that can result from cataract surgery, making lens exchange for purely refractive purposes an increasingly popular option, especially with modern micro-incisionional surgical techniques ${ }^{8}$.

Toric IOLs are a major advance in pseudophakia, although its use is gaining popularity, the literature is poor when it comes to its use in keratoconus patients - an European article reports a foldable toric silicone IOL successfully employed in the management of marked regular corneal astigmatism caused by keratoconus ${ }^{10}$. To our knowledge, this is the first report on foldable hydrophobic acrylic toric IOL used for RLE in stage 2 keratoconus.

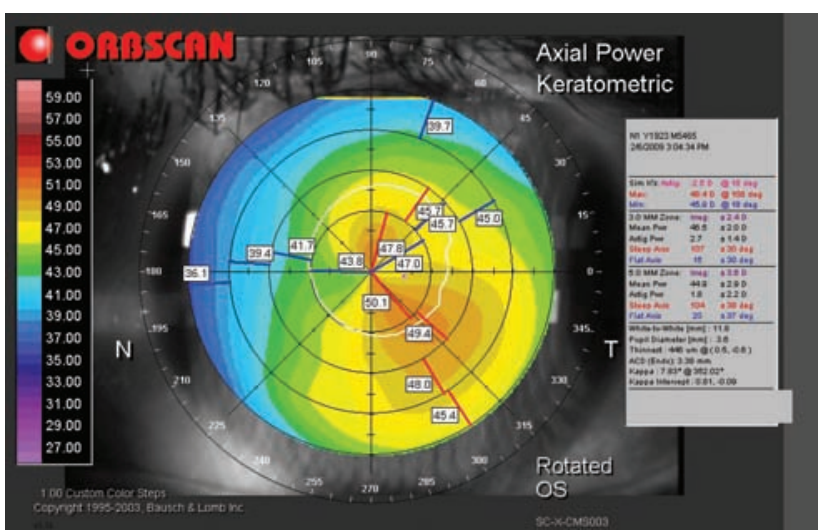

Figure 1: Left eye axial keratometric map

For conventional spherical power-only IOLs, the surgeon essencially needs to select one IOL parameter: its spherical power. With toric IOLs, the surgeon has a further task of choosing the IOL toricity that will compensate that of the cornea. The predictability of its astigmatism correction is good, and little additional time is required to properly position the toric IOL. Intraocular lens spherical power calculation is more predictable in mild keratoconus than in moderate and severe disease ${ }^{8}$. Toric IOLs in keratoconus have, as the main disadvantage, the difficulty in determining axis and power of preoperative astigmatism ${ }^{3}$ - what probably led to some refractive astigmatism undercorrection in our patient. Accurate toric alignment is a fundamental prerequisite for effective refractive correction with toric $\mathrm{IOLs}^{8}$. Each degree of misalignment yields astigmatism undercorrection of $3.3 \%$, with virtually complete loss of IOL cylinder power whenever the IOL is misaligned by 30 degrees $^{9}$. Rotational stability should not be an issue among commercially available toric IOLs, especially with loop haptics ${ }^{3}$. According to the United States Food and Drug Administration trial results, it is apparent that misalignment is largely due to causes other than IOL rotation. These include errors during reference marking and intraoperative marking, or errors related to the surgery itself. Most IOL rotation, if present, happens in the early postoperative period. Once the anterior and posterior capsules fuse, IOL rotation is less likely to occur ${ }^{9}$. The SN60T5 AcrySof Toric IOL has shown excellent postoperative stability, with $95 \%$ of IOLs within 10 degrees of the intended axis of implantation 6 months after surgery ${ }^{10}$. When RLE is considered, keratoconus stability is important to maintain long-term refractive results, because progression would lead to increased corneal myopia and to reduce the risk for future keratoplasty, causing a hyperopic shift by means of a flatter cornea ${ }^{3}$. 


\section{ConcLusion}

In conclusion, the high predictability and good refractive outcomes using toric IOLs could make the use of toric IOLs the standard of care in cataract surgery. Refractive lens exchange employing toric IOL predictably corrected myopia associated with early-stage keratoconus as depicted by this case.

\section{REFERENCES}

1. Colin J, Velou S. Current surgical options for keratoconus. J Cataract Refract Surg. 2003;29(2):379-86.

2. Rosen ES. Ectasia. J Cataract Refract Surg. 2007;33(6):931-2.

3. Leccisotti A. Refractive lens exchange in keratoconus. J Cataract Refract Surg. 2006;32(5):742-6.

4. Gobin L, Rozema JJ, Tassignon MJ. Predicting refractive aniseikonia after cataract surgery in anisometropia. J Cataract Refract Surg. 2008;34(8):1353-61.

5. Neuhann IM, Neuhann TF, Heimann H, Schmickler S, Gerl RH, Foerster MH. Retinal detachment after phacoemulsification in high myopia: analysis of 2356 cases. J Cataract Refract Surg. 2008;34(10):1644-57. Comment in: J Cataract Refract Surg. 2009;35(6):960-1; author reply 9612. J Cataract Refract Surg. 2008;34(10):1613-4.
6. Zuberbuhler B, Seyedian M, Tuft S. Phacoemulsification in eyes with extreme axial myopia. J Cataract Refract Surg. 2009;35(2):335-40.

7. Sauder G, Jonas JB. Treatment of keratoconus by toric foldable intraocular lenses. Eur J Ophthalmol. 2003;13(6):577-9.

8. Thebpatiphat N, Hammersmith KM, Rapuano CJ, Ayres BD, Cohen EJ. Cataract surgery in keratoconus. Eye Contact Lens. 2007;33(5):244-6.

9. Bauer NJ, de Vries NE, Webers CA, Hendrikse F, Nuijts RM. Astigmatism management in cataract surgery with the AcrySof toric intraocular lens. J Cataract Refract Surg. 2008;34(9):1483-8.

10. Hill W. Expected effects of surgically induced astigmatism on AcrySof Toric intraocular lens results. J Cataract Refract Surg. 2008;34(3):364-7. Comment in: J Cataract Refract Surg. 2008;34(9):1425-6.

Corresponding author:

Giuliano de Oliveira Freitas

R. Eduardo Marquez 50, Martins,

ZIP Code 38400-442 - Uberlandia - MG - Brazil

E-mail: gofreitas@ufmg.br

Telephone:+55(34)3230-5050

Facsimile:+55(34)3230-5055 